\title{
Além da compulsão e da escolha: autonomia, temporalidade e recuperação pessoal
}

\author{
Beyond compulsion and choice: \\ autonomy, temporality and personal \\ recovery
}

Este artigo discute a autonomia da pessoa que faz uso problemático de substâncias psicoativas (UPSP). Após o exame da ideia de autonomia de quem faz UPSP, a partir dos paradigmas médico, psicológico e moral, que oscilam entre as compreensões do uso como compulsão ou escolha, discute-se os aspectos psicopatológicos envolvidos no UPSP, em especial a experiência da temporalidade e suas implicações para o debate da autonomia dessas pessoas e para o seu processo de recuperação pessoal.

Palavras-chave: Substâncias psicoativas, autonomia, temporalidade, recuperação pessoal

*1,2,3 Universidade Federal do Rio de Janeiro - UFRJ (Rio de Janeiro, RJ. Brasil). 
O uso problemático de substâncias psicoativas é compulsão ou escolha? Autores que discutem esta temática reconhecem dois grandes modelos, um modelo médico/psicológico e um modelo moral (Henden, Melberg \& Røgeberg, 2013; Kennett, Matthews \& Snoek, 2013; Koopmans \& Sremac, 2011). O modelo médico/psicológico considera o uso como doença, prevalecendo a ideia de que o usuário padece de uso compulsivo e recorrente das substâncias, sobre o qual tem pouco ou nenhum controle, com perda de sua autonomia. $\mathrm{O}$ modelo moral atribui sentido a esse fenômeno considerando o uso como escolha. O comportamento, neste caso, seria voluntário, e o usuário, se desejasse, ou se empenhasse verdadeiramente, sob essa perspectiva, teria controle sobre o uso, já que sua autonomia estaria preservada. Vale dizer que há, todavia, práticas de cuidados, como grupos de ajuda mútua tipo AA, que a despeito do uso de vocabulário médico, estariam mais próximas do modelo moral, na medida em que atribuem ao usuário capacidade de controle sobre o uso. Quais seriam as implicações normativas dessas diferentes formas de ver a questão do uso problemático de substâncias, tanto para quem cuida, como para quem busca ajuda, quando, pela visada da lente do modelo médico/psicológico a autonomia é considerada ausente, e quando, pela perspectiva do modelo moral, a autonomia é reconhecida através da escolha e decisão voluntária de uso? Neste artigo, a proposta é refletir sobre a autonomia do usuário de substâncias psicoativas, a partir das questões colocadas acima, e discutir se haveria outras formas de pensar essa questão, considerando alguns aspectos da psicopatologia do uso de substâncias psicoativas.

\section{Notas sobre a subjetividade e a autonomia}

A subjetividade envolve ideia de autonomia, liberdade, autorreflexividade, autorresponsabilidade, materialidade de um corpo, 
particularidades, potencialidades que conferem cunho próprio e único à personalidade (Souza Santos, 1995). Na modernidade, a ideia de autonomia é representação imediata da liberdade humana. É valor que qualifica e caracteriza o humano e afirma o indivíduo como um princípio (Renault, 1999). No campo da atenção psicossocial a autonomia é também valor importante: não só se trabalha a partir da autonomia possível, como promovê-la é um dos objetivos do cuidado (Leal, Serpa Júnior, Muñoz, Goldenstein \& Delgado, 2006). Na área da atenção aos usuários de álcool e outras drogas, independente do uso abusivo de substâncias ser compreendido como compulsão ou como escolha, o eixo do cuidado organiza-se na sustentação ou ampliação da autonomia do usuário em outros âmbitos da vida, por exemplo, na escolha da forma como lidará com os danos que decorrerão do uso. A autonomia frequentemente é considerada o que de mais importante o processo de tratamento tem a promover. Mas tomar a autonomia do usuário de substâncias a partir de uma dessas diferentes acepções do fenômeno do uso problemático de substâncias teria implicações para a prática de cuidado?

A palavra autônomo vem do grego autos - que quer dizer si mesmo e nomos - que quer dizer lei, regra, norma — ou seja, significa aquele que tem o poder de dar a si mesmo a norma, a regra, a lei. Aquele que goza de autonomia e liberdade seria aquele com capacidade plena de autodeterminação. Todavia, levantado o véu do individualismo, próprio do nosso tempo, percebe-se que a autodeterminação de um sujeito, a sua independência em relação à sociedade e aos elementos que a compõem, é relativa. Num certo sentido, seria mais um mito de nossa cultura, já que essa independência nunca é absoluta. A subjetividade não só é primariamente intersubjetiva, como situada. Ou seja, não existe indivíduo ou pessoa que não sofra as marcas do ambiente de vida. Então, muito mais do que partir da compreensão do sujeito como totalmente livre ou totalmente assujeitado a um ou alguns elementos que compõem o seu mundo, considerados como dois polos diferentes e idealizados dessa questão, interessa conhecer como o sujeito estabelece relação com os elementos que compõem o seu mundo, em especial as substâncias psicoativas, e que tipo de relações seriam essas, partindo do pressuposto de que não haveria ninguém totalmente autônomo e ninguém totalmente determinado pelo ambiente e pelo espaço social. Ou seja, a autonomia e a determinação pelo ambiente e pelos elementos que o compõem são aspectos indissociáveis da subjetividade na contemporaneidade, e operam articuladamente (Leal et al., 2006). Partindo desse pressuposto, concebe-se aqui que a autonomia é a possibilidade de que a determinação do ambiente seja vivida não como assujeitamento, mas 


\section{OBSERVANDO A PSIQUIATRIA}

apropriada pelo sujeito, seja vivida como autogoverno, como experiência que preserva algum senso de agência. A perspectiva autoral, que dá à pessoa a vivência de expressão autêntica e peculiar do seu self, em relação ao ambiente, define, então, o sentido adotado aqui para autonomia.

\section{Notas sobre a psicopatologia do uso de substâncias — a questão da temporalidade}

As substâncias psicoativas produzem alterações do humor, do comportamento ou da cognição e assim alteram o estado mental de quem as utiliza. Outros elementos presentes na vida cotidiana, além das drogas — sono, cansaço intenso, pavor etc. - também podem alterar o estado da consciência, ou seja, o padrão de atividade perceptiva, cognitiva e/ou afetiva que se experimenta a cada momento. Em geral, a discussão sobre os efeitos que as drogas podem produzir sobre o estado mental se faz quase que exclusivamente a partir das características farmacológicas dessas substâncias. Tais características não são, todavia, os únicos elementos que influem sobre a experiência que a pessoa terá com a substância, como frequentemente se crê. $\mathrm{O}$ estado mental anterior ao uso, a personalidade da pessoa, o modo como a pessoa experiencia o seu corpo, a sua relação com o meio, o ambiente em que se encontra e do qual faz parte, todos esses elementos concorrerão para a qualidade da experiência vivida.

Estudos, principalmente aqueles que levam em conta as descrições subjetivas dos usuários, mostram que a variabilidade no tipo de experiência não se dá apenas entre usuários de substâncias diferentes, como se costuma reconhecer, mas também entre usuários de uma mesma substância. A substância apresenta-se como um, mas não o único elemento, a determinar a qualidade da experiência vivida. Os contornos dessa experiência, o seu colorido, seria um fenômeno mais complexo que decorreria da articulação desses diversos elementos.

Há entretanto, nesses relatos, um aspecto que é comum à alteração do estado de consciência provocado pelo uso das diversas substâncias psicoativas: a alteração do tempo vivido (Messas, 2014; Messas, Vitucci, Garcia, Dutra \& Souza, 2016; Moskalewicz, 2016). A experiência da temporalidade se modifica com o uso das substâncias psicoativas. Contudo, mais do que apenas um efeito do uso de diferentes substâncias psicoativas, outra experiência da temporalidade se apresenta como uma espécie de solo ou fundamento sobre 
o qual se assentam o uso nocivo ou dependência de substâncias, assim como outros comportamentos ditos compulsivos (Kemp, 2009). Nessa outra forma de vivenciar a temporalidade a amplificação e aprisionamento do sujeito num tempo presente lhe proporciona uma experiência de presente absoluto. Passado e futuro, ausentes como dimensões constitutivas do presente, fazem com que o presente se torne uma mera coleção de instantes, com perda da perspectiva do fluxo da vida e consequente perda da dimensão biográfica da existência. A pessoa passa a experimentar a vida como uma sequência de instantes sem historicidade. A mudança da experiência da temporalidade parece ser a mais básica e aquela que por ser comum servirá de estrutura e base para as demais alterações, inclusive aquelas que nos permitirão discutir a autonomia das pessoas que fazem uso de substâncias psicoativas.

\section{Notas sobre o debate da autonomia no contexto do uso abusivo de substâncias — compulsão, escolha, prazer?}

O debate sobre a autonomia de quem faz uso problemático de substâncias psicoativas é central para a concepção do problema do uso e para o desenho das práticas e ações de cuidado. Embora tal debate possa não estar explicito, é possível deduzi-lo a partir de várias ideias compartilhadas por profissionais de saúde, usuários, familiares e sociedade. Apresentaremos algumas delas e, a seguir, explicitaremos os pressupostos sobre a autonomia que as sustentam:

- "as pessoas [que fazem uso problemático de substâncias psicoativas] ficam todas fora de si";

- "As pessoas [que fazem uso problemático de substâncias psicoativas] agem movidas pela droga", ou " a droga dirige e move as pessoas";

- "Não adianta tratar quem não quer";

- "Perdemos tempo cuidando dele, enquanto outras pessoas que realmente precisam ficam desassistidas";

- "se você quer beber o problema é seu, se quer parar é nosso".

Ideias de que os usuários ficam fora de si ou de que são movidos pela droga sugerem, implicitamente, que o uso problemático decorre da incapacidade da pessoa se autodeterminar. Essa incapacidade frequentemente está ancorada na noção de compulsão à droga, eixo central do modelo de compreensão reconhecido na bibliografia como o modelo médico/psicológico. Nessa 
perspectiva, o usuário, dominado por uma vontade incoercível de usar, mesmo que alguma crítica racional ao uso esteja presente, perderia a sua capacidade de livre escolha, já que a compulsão, ato específico que se repete e que o sujeito é incapaz de deter, o assujeitaria.

O modelo médico/psicológico pode ser explicado por concepção biologicista, psicológica ou ambas. Quando a base do modelo é biológica, um "distúrbio cerebral crônico, com recidivas" (Koopmans \& Sremac, 2011), transformaria o usuário em alguém mentalmente incapaz de tomar decisões. Esta "doença", estabelecida por mecanismos patológicos cerebrais, retiraria da pessoa a capacidade de controle sobre seus atos. Embora os usuários possam experimentar também a vontade de não usar, essa vontade não teria influência sobre a pessoa porque eles estariam incapazes de decidir racionalmente, a não ser que estivessem em estágios muito iniciais da doença. Resumindo, o modelo da doença, ao enfatizar a compulsão e a perda do controle, oferece uma compreensão da pessoa como "autômatos sem sentido", vítimas da droga, dominados pela força de mecanismos patológicos biológicos, psicológicos ou ambos. Quando os fenômenos psicológicos são tomados como base da compulsão, ela é considerada expressão de conflito interno, diante do qual a pessoa não consegue se posicionar.

Como citado acima há outras ideias correntes, comuns tanto entre leigos quanto entre profissionais, pautadas sobre outros pressupostos. Elas sustentam que não adianta tratar quem não quer, ou que o uso da bebida é um problema privado. Subjacente a elas, está a noção de que o uso de substâncias psicoativas é uma escolha autônoma e que quem o faz é moralmente responsável por tal escolha. Sob esta perspectiva as pessoas não são vítimas de sua doença, não sofreriam de transtorno compulsivo. Ato volitivo, o uso das drogas aconteceria porque as pessoas querem fazê-lo. Estes aspectos caracterizariam o que foi nomeado de modelo moral ou modelo de escolha.

Em geral, o modelo moral ou de escolha pressupõe que a escolha pelo uso abusivo de drogas seja um comportamento orientado para o prazer. Se o sofrimento se apresenta, é entendido prioritariamente como fruto da forte desaprovação social e moral a que estão submetidas, em nossa sociedade, as pessoas que orientam suas vidas para e pelo prazer, a despeito das perdas sociais e de saúde associadas ao uso. Esses aspectos poderiam levar o usuário a sistematicamente se arrepender de seu comportamento de consumo, mas não transformaria a decisão de usar a droga menos autônoma ou racional. Haveria uma escolha deliberada pelo prazer, a despeito do reconhecimento das suas consequências morais, sociais e de saúde. 
Nos modelos explicativos apresentados, a autonomia ou está presente ou está perdida. Há, entretanto, autores que discutem o tema da autonomia no contexto do uso abusivo de drogas em outros termos, e sugerem que o debate sobre autonomia da pessoa que faz uso problemático de substâncias psicoativas não pode se dar pautado em esquema que simplesmente oponha a autonomia, enquanto capacidade de se autodeterminar, à compulsão, tomando esses dois fenômenos como polos diametralmente opostos, não contíguos, e qualitativamente diversos. Alguns dos argumentos apresentados a seguir sustentam essa posição.

Henden, Melberg e Røgeberg (2013), ao argumentarem que o comportamento compulsivo não necessariamente exclui o comportamento voluntariamente escolhido, sugerem a insuficiência dos modelos médico/ psicológico (centrado exclusivamente na ideia da doença/compulsão) e moral (que qualifica o uso como mera escolha passível de controle). A relação com o comportamento repetitivo orientado à droga, afirmam, é sim passível de modificação, e não é indiferente a estímulos nem totalmente involuntário, como nos lembra a clínica. A sugestão estaria na base da compulsão, na medida em que lugares e pessoas influenciam o comportamento compulsivo, embora, aparentemente, não se perceba nenhum controle. Certas características do processo de tomada de decisão evidenciariam isso. Dentre eles, citam a presença, nas pessoas que fazem uso abusivo de drogas, de intenção de modificar o estado de humor, regular afeto etc. Para esses autores, nos casos de uso abusivo, a alteração estaria no sistema de tomada de decisão. Constituído por dois componentes — um rápido e intuitivo, relacionado à aprendizagem implícita, não reflexivo, que se automatiza e é amplamente marcado por fatores biológicos, e outro mais lento, analítico, intensamente determinado pela cultura, que requer atenção controlada e esforço -; ambos deveriam trabalhar juntos para a tomada racional de decisão, mas estariam dissociados em quem faz uso abusivo de drogas.

Outros autores, pautados em outros argumentos, também discutem a oposição entre autonomia (de escolha da droga, e determinação pela droga), sugerida pelos modelos moral e médico/psicológico. Koopmans e Sremac (2011), em artigo em que discutem os dois modelos, a partir de uma revisão de trabalhos que sustentam cada uma dessas perspectivas, argumentam que pessoas que fazem uso problemático de substâncias psicoativas frequentemente experimentam a vontade de interromper o uso, mas mudam de ideia quando lhes surge a oportunidade de consumi-las, ou a fissura, ou, ainda, os prazeres proporcionados pelo uso pesam mais do que os ganhos do uso 


\section{OBSERVANDO A PSIQUIATRIA}

controlado ou da abstinência. Quando isso acontece, afirmam, o que se observa é o sacrifício do interesse a longo prazo. O interesse a curto prazo, ou seja, a escolha pelo uso naquele momento, ganha lugar a partir de uma mudança do julgamento. A pessoa escolhe a gratificação imediata de seu desejo, que naquele momento parece ser a escolha racionalmente com maior sentido do que o não uso ou o uso controlado. Esses autores não apostam na ideia de um "defeito" da vontade, ou incapacidade de escolha. Por que? Porque não acham que essas pessoas não conseguem fazer outras escolhas. A discussão que estabelecem recusa então a visão dos usuários como autômatos, movidos pela droga, mas também a visão de que são pessoas que escolhem sem conflitos, ou apenas com conflitos produzidos exclusivamente pela força do julgamento exterior.

Kennett, Matthews \& Snoek (2013) sugerem, ao discutirem o papel do prazer no uso problemático de substâncias psicoativas a partir de estudo qualitativo em que entrevistam 69 pessoas, que a motivação do uso problemático é complexa, não passível de redução exclusivamente à fraqueza da vontade ou compulsão, nem à escolha autônoma e livre. Nas narrativas estudadas, eles reconhecem os dois modelos. O modelo moral, dizem, seria adequado para explicar o que se passou com certo grupo de usuários, aqueles capazes de deixar o uso prejudicial de drogas após a aquisição de novos interesses e responsabilidades. Não se aplicaria, todavia, aos usuários que chamam do núcleo duro, aqueles com uso mais grave, e que preocupam mais os profissionais de saúde. Estes teriam mais dificuldades em mudar o padrão de consumo e por isso teriam o seu comportamento melhor descrito pelo modelo médico/ psicológico, que descreve o uso a partir da perda de autonomia, em geral determinada pela compulsão. Concluem, então, propondo que a autonomia seja pensada numa perspectiva processual, de um contínuo com diferentes graus.

Há outro aspecto explicitado por esses autores, perceptível apenas implicitamente nos demais trabalhos, que recusam a redução do uso problemático de substâncias a um dos dois modelos apresentados acima, que merece destaque. Esse aspecto contém uma chave que pode ser útil para que a questão da autonomia de quem faz uso abusivo de substâncias psicoativas não seja tematizada exclusivamente a partir da sua presença ou ausência, independente da adoção de um dos dois modelos. Esses autores afirmam que a autonomia é um fenômeno que só pode ser pensado sob uma perspectiva diacrônica. Ao introduzirem a temporalidade como elemento central para a discussão da autonomia de quem faz uso problemático de substâncias psicoativas, os 
autores apostam que a atividade diacrônica é condição para a autonomia. Destacam que o exercício da autonomia requer necessariamente a capacidade de lembrar o passado e projetar o futuro, tanto quanto a capacidade de planejar. Essa leitura da autonomia, que tem na temporalidade um elemento central, permite que se examine e discuta a possibilidade de uma psicopatologia da autonomia do uso problemático de substâncias psicoativas, questão que dirigirá o item seguinte.

\section{Notas sobre uma psicopatologia da autonomia no uso problemático de substâncias psicoativas a partir da questão da temporalidade}

Em item anterior, sublinhamos que as descrições subjetivas dos usuários de substâncias psicoativas sugerem que há uma enorme variabilidade no tipo de experiência que se tem com as drogas e que tal diversidade não está na dependência exclusiva do tipo de substâncias, mas é perceptível também entre usuários de uma mesma substância. Isso indica que a substância não é o único elemento a determinar a qualidade da experiência vivida, muitos outros elementos - dentre eles, o estado mental anterior ao uso, a personalidade da pessoa, o modo como a pessoa experiencia o seu corpo, sua relação com o meio, o ambiente em que se encontra e do qual faz parte - concorrem para a qualidade da experiência vivida, revelando a complexidade desse fenômeno.

A alteração do tempo vivido atravessa a experiência subjetiva de quem faz uso problemático de substâncias psicoativas para além dos efeitos momentâneos de seu uso. A mudança da experiência da temporalidade é solo comum, estrutura e base para as demais alterações. A temporalidade da vida, reduzida ao instante presente amplificado, aprisiona o sujeito num tempo em que passado e futuro estão esmaecidos ou mesmo banidos. O presente, tornado mera coleção de instantes, deixa de ser vivido como fluxo da vida.

Reafirmando aqui a característica básica da experiência do tempo nos sujeitos que fazem uso nocivo ou se tornam dependentes de substâncias psicoativas, a pergunta que dirige este artigo se recoloca, agora em outros termos: que autonomia é possível quando o presente é vivido como simples sequência de eventos, sem qualquer alusão ao passado vivido e ao futuro imaginado?

Para fins do debate travado aqui, a autonomia foi definida como possibilidade de que a determinação do ambiente que todos sofremos, seja vivida não exclusivamente como assujeitamento, mas apropriada pelo sujeito, experimentada como autogoverno e com preservação do senso de agência que nos 


\section{OBSERVANDO A PSIQUIATRIA}

constitui a todos. O senso de agência e autogoverno, de apropriação das influências do ambiente com autoria, todavia, são improváveis numa perspectiva temporal plana, que não envolva a experiência de passado e futuro, sempre atualizadas no presente. O planejamento e o autocontrole, outras dimensões da experiência de autonomia, também só são possíveis se a vida for experienciada como fluxo contínuo, envolvendo a vivência da temporalidade em toda sua extensão e complexidade. Assim, cabe perguntar se a experiência da autonomia vivida numa perspectiva exclusivamente sincrônica — situação própria a quem faz uso problemático de substâncias psicoativas - guardaria as mesmas características que a experiência de autonomia vivenciada cotidianamente, quando operam tanto a perspectiva sincrônica quanto a diacrônica. Considerando a hipótese de que haveria diferenças na experiência de autogoverno vivida na vida cotidiana comum e quando a pessoa faz uso problemático de substâncias psicoativas, caberia simplesmente afirmar que a autonomia estaria ausente, como supõe o modelo médico/psicológico, ou presente, como sugere o modelo moral?

A experiência do tempo, que pode ser tanto transformada pelo consumo de substâncias psicoativas quanto o solo de seu uso nocivo, modifica as condições de produção da autonomia como a conhecemos. O estreitamento da temporalidade da consciência ao instante modifica também outros elementos que determinam a qualidade da experiência vivida. A existência, subjugada ao instante, altera, por exemplo, a capacidade de o sujeito individualizar-se no tempo e concorre para um estreitamento identitário. A potência de modificação da identidade, quando passado e futuro são enfraquecidos enquanto possibilidade experiencial, também fica reduzida. Observa-se ainda que a materialidade vivida, aquela experimentada nesse presente sem passado e sem futuro, tende a se ampliar (Messas, 2014; Messas et al., 2016). A hipertrofia do presente nos leva inclusive a deslocar a questão da impulsividade/perda de autonomia versus escolha moral, cara ao debate entre o modelo biomédico e o modelo moral, mencionados acima, para o reconhecimento de uma paradoxal hiperautonomização do sujeito, que descolado de uma temporalidade intersubjetiva (Fuchs, 2013) da trajetória autobiográfica entrelaçada com outras biografias, e do futuro projetado em ações coletivas, se ancora em um aqui-e-agora do corpo e das circunstâncias imediatas. Com todas essas mudanças, faria sentido supor que a experiência de autonomia de quem faz uso abusivo de substâncias e de quem não faz, sejam pensadas nos mesmos termos?

O CSMN - Centro de Estudos da Mente na Natureza - centro de excelência em pesquisa sobre os aspectos característicos da mente 
humana, com foco em temas tais como agência moral, racional e linguística, da Universidade de Oslo, realizou, em junho de 2014, evento chamado Addiction, disease and choice (Dependência, doença e escolha). Nesse encontro, que reuniu vários estudiosos do tema de todo o mundo, o eixo da discussão foi a necessidade de superar a dicotomia entre o modelo médico/ psicológico e o modelo moral. Esse grupo argumentava que mesmo que o uso problemático de substâncias envolva padrões compulsivos de comportamento, isso não significa necessariamente que as pessoas com tais comportamentos não tenham nenhum controle sobre o uso das drogas (Henden, Røgeberg, Johansen, Melberg, Gjelsvik \& Gammelsaeter, 2014). Discussões filosóficas e estudos empíricos os incentivavam a desenvolver outras possibilidades de compreensão da questão da autonomia nesse contexto. Todos, a despeito das diferenças teóricas e metodológicas existentes entre eles, partiam de um ponto comum. Compartilhavam, como hipótese de trabalho, que a autonomia inclui a capacidade de se relacionar, formar relações pessoais próximas, compreender o sentimento dos outros e responder a pressões normativas colocadas sobre alguém pelos outros e que a condição necessária para tal capacidade é um tipo de interação entre o comportamento da pessoa, a responsividade 140 do ambiente a esse comportamento, e vice-versa, além da autoavaliação da sua performance. A partir dessa definição, propunham-se a investigar se o comprometimento involuntário de tal capacidade modificaria a autonomia de quem faz uso problemático de substâncias.

Três desses trabalhos serão destacados aqui porque, indiretamente, sugerem que a capacidade que determina a autonomia, acima citada, bem como a sua condição de possibilidade se modificam quando a experiência da temporalidade muda. O primeiro trabalho é de Carl Hart (2014), um autor conhecido no Brasil através das mídias leigas. Nesse encontro, ele apresentou o resultado de duas pesquisas. Uma com usuários de anfetaminas; outra com usuários de cocaína/crack. Nos dois estudos, ele observa que ofertado aos usuários grandes quantidades de drogas e valores em dinheiro, quando o valor em dinheiro era pequeno (5 dólares), metade dos usuários escolhiam o dinheiro e a outra metade a droga, se o valor em dinheiro subisse para 20 dólares, todos os usuários escolhiam o dinheiro.

O outro trabalho, de autoria de Pickard e Ahmed (2014), discutia por que as pessoas que fazem uso problemático de substâncias persistem no uso mesmo conhecendo as suas consequências negativas. A partir da consideração de aspectos neurobiológicos, filosóficos e empíricos, os autores observam que essas pessoas não têm "interesse" pelo futuro, mas respondem positivamente a 


\section{OBSERVANDO A PSIQUIATRIA}

recompensas presentes, em especial às sociais, relacionadas com o seu mundo real, com o seu contexto psicossocioeconomico direto e vivencial. O último dos trabalhos, de Railton (2014), melhor descrito no parágrafo seguinte, ao discutir o desejo sustentava que as representações afetivas deixam de exercer controle efetivo da motivação.

Destacamos esses três trabalhos porque, por caminhos diferentes, todos eles, diretamente ou não, mostram que a mudança da experiência da temporalidade pode estar na base das alterações e observações que descrevem. No estudo de Hart (2014), percebe-se que se a oferta de dinheiro é algo com impacto imediato no presente -5 dólares talvez não tivesse, mas 20 , é bem provável que sim - todas as pessoas, nos dois estudos, escolhem o dinheiro. No caso do trabalho de Pickard e Ahmed (2014), de forma direta eles afirmam que as pessoas não têm interesse no futuro, mas respondem positivamente a recompensas presentes se tais recompensas tiverem conexão direta com o seu contexto vivencial imediato. No último estudo, Railton (2014) reconhece que representações afetivas deixam de ter controle sobre a motivação. A pergunta que fica implícita é se é possível que as representações afetivas preservem o seu colorido emocional e não se apresentem esmaecidas e sem força se o presente for experimentado como mera coleção de instantes, sem passado e presente, e com pouca ou nenhuma perspectiva biográfica. Todas essas reflexões nos propõem a última questão que abordaremos neste artigo: quando a questão da autonomia é debatida nos termos propostos neste trabalho, é possível pensar na recuperação pessoal ${ }^{1}$ como um processo a ser atravessado pela pessoa que faz uso abusivo de substâncias psicoativas?

\section{Notas sobre a recuperação pessoal de pessoas que fazem uso abusivo de substâncias psicoativas}

Anthony (1993), que tem uma das mais citadas definição de recovery, o define como experiência pessoal:

Recovery é um processo profundamente pessoal, único, de mudança de atitudes, valores, sentimentos, metas, habilidades e/ou papéis. É uma maneira de viver uma vida satisfatória, esperançosa e contributiva, mesmo dentro das

\footnotetext{
${ }^{1}$ Optamos por traduzir o conceito de recovery, que será discutido adiante no texto, por recuperação pessoal.
} 
limitações causadas pelo adoecimento. Recovery envolve o desenvolvimento de um novo significado e propósito na vida de alguém, uma vez que cresce para além dos efeitos catastróficos do adoecimento mental. (p. 527; tradução nossa)

A recuperação pessoal (Personal Recovery) surgiu do movimento dos usuários (Davidson \& Roe, 2007; Deegan, 1988; O’Hagan, 2013) e se associou a uma compreensão já existente — recuperação clínica (clinical recovery) — fruto de pesquisas e práticas lideradas por profissionais. Compreendido como processo vivido a partir da experiência pessoal, a recuperação pessoal enfatiza a centralidade da esperança, a identidade, o significado e a responsabilidade social (Slade \& Davidson, 2011). Embora tenha surgido, originalmente, no campo dos transtornos mentais graves e persistentes, o debate sobre o que seria o movimento da recuperação pessoal no campo do uso problemático de substâncias psicoativas tem crescido. $\mathrm{O}$ aspecto que permite a aproximação dos dois campos é evidente: a tradição da recuperação pessoal não tem como eixo a presença ou ausência do desejo de se tratar, mas as questões que importam para aquela pessoa em particular, naquele momento histórico da sua experiência de vida, eixo central do projeto de cuidado.

O movimento de recuperação pessoal mostrou que o transtorno mental grave e persistente, tanto quanto o uso problemático de substâncias, são incapazes de definir quem é uma pessoa ou definir o que ela será para o resto de sua vida (Davidson, apud White, 2013). Estudos sobre recuperação pessoal no campo $\mathrm{AD}$, embora ainda sejam bem menos numerosos do que entre as pessoas que têm transtornos mentais graves e persistentes, sugerem que usuários de serviços dessa área também experimentam a recuperação como um processo e jornada pessoal, que diz respeito a "lidar" com a vida, muito mais do que a "curar" um problema de saúde.

Davidson e Roe (2007) mostram que os recursos financeiros, materiais e instrumentais, o sentimento de pertencimento a um grupo ou comunidade e a possibilidade de contar com uma rede de apoio, devem ser considerados o capital de recuperação pessoal de uma pessoa. Quanto menor seu capital de recuperação pessoal, mais ajuda a pessoa precisará durante o processo, que pode ser longo e incluir diferentes fases (o momento que antecede a recuperação pessoal, o início do processo, a estabilização e/ou a manutenção). Neale et al. (2015) entendem a recuperação pessoal como uma experiência altamente individualizada que depende de muitos fatores, que envolvem gênero, idade, padrão de uso, fase de recuperação pessoal e outras circunstâncias pessoais. Os autores enfatizam que a recuperação pessoal é um processo doloroso, 
que exige esforço, mas que pode também ser vivido como uma experiência motivadora, interessante e positiva. Para além de uma mudança racional de comportamento, a recuperação pessoal envolve mudanças físicas e emocionais involuntárias e espontâneas que precisam ser reconhecidas e gerenciadas.

White (2007) aponta que a definição de recuperação pessoal no campo $\mathrm{AD}$ deve ser ampla o suficiente para não encerrá-lo em um quadro específico, abarcando diferentes estilos e estratégias pelos quais pode ser alcançado. A definição de recuperação pessoal deve impactar a vida de pessoas que fazem uso de substâncias psicoativas e de seus familiares, além de influenciar a visão social sobre o tema. Esse autor propõe considerar a recuperação pessoal como uma experiência que se relaciona com os recursos internos e externos utilizados pelas pessoas e seus familiares para minimizar os danos e gerenciar a vulnerabilidade pessoal em relação aos problemas causados pelo uso de substâncias e desenvolver uma vida produtiva e significativa para a pessoa. Diferentes padrões de uso de substâncias podem acarretar variações em relação à gravidade, complexidade e duração do problema.

A resolução de problemas ligados ao uso de substâncias psicoativas pode se dar em vários níveis, abrangendo pessoas (a) que são completamente abstinentes; (b) que são essencialmente abstinentes (baixo volume de consumo, ocasiões raras que não resultam em problemas mensuráveis); (c) que continuam a usar, mas apresentam um padrão subclínico de uso; (d) que atendem aos critérios do DSM - Manual Diagnóstico e Estatístico de Transtornos Mentais — de abuso/dependência, nos diferentes níveis de gravidade do problema.

No que se refere à relação entre abstinência e recuperação pessoal, o autor indica que é preciso saber se a abstinência é realmente um elemento determinante da recuperação pessoal ou apenas uma das muitas estratégias para alcançá-lo, pergunta que só pode ser respondida a partir da experiência da pessoa envolvida. No contexto da saúde global, a resolução de problemas ligados ao uso de substâncias psicoativas não deveria ser vista como um ponto isolado, mas como um subproduto de processos pessoais e interpessoais maiores. Por exemplo, alguém que alcançou a abstinência estaria em recuperação pessoal se alcançou também níveis de saúde física, emocional e/ou relacional que contribuam para o desenvolvimento de um significado e propósito na vida mais satisfatório para si.

É possível que as questões que importam para aqueles que fazem uso problemático de substâncias psicoativas não estejam imediatamente evidentes nem para essas pessoas nem para quem cuida, já que essas pessoas, 
"aprisionadas" no tempo presente, podem ter a sua história biográfica enfraquecida, enquanto elemento capaz de dirigir ou atribuir sentido às suas escolhas. Para essas pessoas, é possível que sua história tenha que ser recuperada a partir de pequenos e simples elementos da vida mais básica, cotidiana e imediata.

Assim como no campo dos transtornos mentais, no campo do uso problemático de drogas, descrever o comportamento e os sintomas não é suficiente para a construção de um cuidado sensível à experiência da pessoa. No contexto do uso abusivo da droga, se a biografia está esmaecida, a experiência peculiar que cada pessoa tem com dada substância e a experiência que cotidianamente vivencia com o seu corpo e o espaço que habita podem ser elementos que ajudem a superar a descrição generalizante dos usuários, e abrir portas para que as peculiaridades que são próprias à vida de cada sujeito ganhem novamente cor e visibilidade. Nesse sentido, a própria experiência de alteração de consciência vivida por cada um com a substância, que sofre influência direta do estado mental anterior ao uso, da personalidade da pessoa, do modo como a pessoa experiencia o seu corpo, a sua relação com o meio, o ambiente em que se encontra e do qual faz parte, pode ser uma pista oferecida pelo presente para que o passado e futuro esmaecido nessa experiência sejam paulatinamente recuperados e cerzidos novamente ao presente.

Agradecimentos: Agradecemos a Julia Chindler e Chen Xuewu pelas versões do resumo em alemão e mandarim.

\section{Referências}

Anthony, W. A. (1993). Recovery from mental illness: The guiding vision of the mental health service system in the 1990s. Psychosocial rehabilitation jornal, 16(4), 521-538. Recuperado em 20 fev. 2019, de: <https://recoverydevon. co.uk/wp-content/uploads/2010/01/Recovery_from_Mental_Illness_ Anthony_1993.pdf>.

Davidson, L., \& Roe, D. (2007). Recovery from versus recovery in serious mental illness: One strategy for lessening confusion plaguing recovery. Journal of Mental Health, 16 , 459-470. doi: 10.1080/09638230701482394.

Deegan, P. E. (1988). Recovery: The lived experience of rehabilitation. Psychosocial Rehabilitation Journal, 11(4), 11-19. doi: 10.1037/h0099565.

Foddy, B., \& Savulescu, J. (2010). A liberal account of addiction. Philosophy, 


\section{OBSERVANDO A PSIQUIATRIA}

psychiatry, \& psychology, 17(1), 1-22. doi: 10.1353/ppp.0.0282.

Fuchs, T. (2013). Temporality and psychopathology. Phenomenology and the cognitive sciences, 12(1), 75-104. doi: 10.1007/s11097-010-9189-4.

Hart, C. (2014, June). Ask the wrong question, get the wrong answer. In E. Henden, O. Røgeberg, A. Johansen, O. H. Melberg, O. Gjelsvik, \& F. Gammelsaeter (Orgs.). Addiction, Disease and Choice. Abstracts. Research workshop. CSMN - Center for the Study of Mind in Nature. Oslo, Norway. Recuperado em 20 fev. 2019, de: $<$ https://www.hf.uio.no/csmn/english/csmn_annual_report_2014_web.pdf $>$.

Henden, E., Melberg, H. O., \& Røgeberg, O. J. (2013). Addiction: choice or compulsion? Frontiers in psychiatry, 4, 1-11. doi: 10.3389/fpsyt.2013.00077.

Henden, E., Røgeberg, O., Johansen, A., Melberg, O. H., Gjelsvik, O. \& Gammelsaeter, F. (Orgs.). (2014, June). Addiction, Disease and Choice. Abstracts. Research workshop. CSMN - Center for the Study of Mind in Nature. Oslo, Norway. Recuperado em 20 fev. 2019, de: <https://www.hf.uio.no/csmn/english/ csmn_annual_report_2014_web.pdf $>$.

Kemp, R. (2009). The temporal dimension of addiction. Journal of Phenomenological Psychology, 40(1), 1-18. doi: 10.1163/156916209X427963.

Kennett, J., Matthews, S., \& Snoek, A. (2013). Pleasure and addiction. Frontiers in psychiatry, 4, 1-11. doi: 10.3389/fpsyt.2013.00117.

Koopmans, F. \& Sremac, S. (2011). Addiction and Autonomy: are Addicts Autonomous? Nova prisutnost: časopis za intelektualna i duhovna pitanja, 9(1), 171-188. Recuperado em 20 fev. 2019, de: <https://www.researchgate.net/ publication/235952826_Addiction_and_Autonomy_are_Addicts_Autonomous $>$.

Larry D., White W., Sells D., Schmutte T., O’Connell M., Bellamy, C., \& Rowe, M. (2010). Enabling or engaging? The role of recovery support services in addiction recovery. Alcoholism Treatment Quarterly, 28(4), 391-416. doi.10.1080/073473 24.2010.511057.

Leal, E. M., Serpa Júnior, O. D., Muñoz, N. M., Goldenstein, N., \& Delgado, P. G. G. (2006, set.). Psicopatologia da autonomia: a importância do conhecimento psicopatológico nos novos dispositivos de assistência psiquiátrica. Revista Latinoamericana de Psicopatologia Fundamental, 9(3), 433-446. doi: 10.1590/1415-47142006003005.

Messas, G. (2014). On the essence of drunkenness and the pathway to addiction: A phenomenological contribution. J Addict Behav Ther Rehabil, 3, 2. doi:10.4172/2324-9005.1000121

Messas, G., Vitucci, L., Garcia, L., Dutra, R., \& Souza, J. (2016). Por uma psicopatossociologia das experiências dos usuários de drogas nas cracolândias/ cenas de uso do Brasil. In J. Souza (Org.), Crack e exclusão social (pp.163190). Brasília, DF: Ministério da Justiça e Cidadania, Secretaria Nacional sobre 
políticas sobre drogas.

Moskalewicz, M. (2016). Lived time disturbances of drug addiction therapy newcomers. A qualitative, field phenomenology case study at Monar-Markot Center in Poland. International Journal of Mental Health and Addiction, 14(6), 1023-1038. Doi: 10.1007/s11469-016-9680-4.

O’Hagan, M. (2013). Recovery and wellbeing. In L. Knifton, \& N. Quinn (Eds.), Public mental health: global perspectives (pp. 83-93). UK: McGraw-Hill Education.

Pickard, H., \& Ahmed, S. Addiction, Choice, Foresight. (2014, June). In E. Henden, O. Røgeberg, A. Johansen, O. H. Melberg, O. Gjelsvik, \& F. Gammelsaeter (Orgs), Addiction, Disease and Choice. Abstracts. Research workshop. CSMN - Center for the Study of Mind in Nature. Oslo, Norway. Recuperado em 20 fev. 2019, de: $<$ https://www.hf.uio.no/csmn/english/csmn_annual_report_2014_web.pdf>

Railton, P. (2014, June). Two kinds of failure to learn in desire. In E. Henden, O. Røgeberg, A. Johansen, O. H. Melberg, O. Gjelsvik, \& F. Gammelsaeter (Orgs), Addiction, Disease and Choice. Abstracts. Research workshop. CSMN - Center for the Study of Mind in Nature. Oslo, Norway. Recuperado em 20 fev. 2019, de: <http://www.hf.uio.no/csmn/english/research/news-and-events/events/ conferences/2014/oslo-addiction-workshop-2014.html>.

Renault, A. (1999). Avant-propos: Liberté, Egalité, Subjectivité. In A. Renault (Org.), Histoire de la philosophie politique. Tome II: Naissances de la Modernité. Paris, France: Éditions Calmann-Lévy.

Slade, M., \& Davidson, L. (2011). Recovery as an integrative paradigm in mental health. In G. hornicroft (Ed.), Oxford textbook of community mental health (pp. 26-33). UK: Oxford University Press.

Souza Santos, B. (1995). Pela mão de Alice. O social e o político na pós-modernidade. Porto, Portugal: Edições Afrontamento.

White, W. L. (2007). Addiction recovery: Its definition and conceptual boundaries. Journal of substance abuse treatment, 33(3), 229-241. doi: 10.1016/j. jsat.2007.04.015.

White, W. L. (2013). Contrasting perspectives on recovery: An interview with Larry Davidson, PhD, Department of Psychiatry, Yale University School of Medicine. Recuperado em 20 fev. 2019 de: <http:/www.williamwhitepapers.com/ pr/2013\%20Dr.\%20Larry\%20Davidson.pdf>. 


\section{OBSERVANDO A PSIQUIATRIA}

\section{Resumos}

(Beyond compulsion and choice: autonomy, temporality and personal recovery)

This paper discusses the autonomy of subjects engaged in substance misuse (SM). After examining the concept of autonomy of subjects engaged in SM, based on medical, psychological and moral paradigms that range between understanding SM either as a compulsion or a choice, we discuss the psychopathological aspects involved in SM, i.e., the experience of temporality and its implications regarding the autonomy of these subjects and their recovery process.

Key words: Psychoactive substances, autonomy, temporality, personal recovery

(Au-delà de la contrainte et du choix: autonomie, temporalité et rétablissement personnel)

Cet article discute l'autonomie de personnes sujettes à l'utilisation problématique de substances psychoactives (UPSP). Après avoir élaboré la notion d'autonomie de ces sujets à partir de paradigmes médicaux, psychologiques et moraux qui comprennent l'UPSP soit comme une contrainte, soit comme un choix, on discute les aspects psychopathologiques liés à l'UPSP, en particulier l'expérience de la temporalité et ses implications pour le débat sur l'autonomie de ces personnes et leur processus de rétablissement.

Mots clés: Substances psychoactives, automomie, temporalité, rétablissement

(Mas allá de la compulsión y la elección: autonomía, temporalidad y recuperación)

Este artículo discute la autonomía de la persona que sufre con el consumo problemático de sustancias psicoactivas (CPSP). Después examinar la idea de autonomía en quien tiene un CPSP, a partir de los paradigmas médico, psicológico y moral, que oscilan entre las comprensiones del uso como compulsión o elección, se discuten los aspectos psicopatológicos involucrados en el CPSP, en especial en la experiencia de la temporalidad, y sus implicaciones para el debate de la autonomía de esas personas y para su proceso de recuperación personal.

Palabras clave: Sustancias psicoactivas, autonomía, temporalidad, recuperación

(Jenseits von Zwang und Wahl: Autonomie, Temporalität und Rehabilitation)

Dieser Artikel ergründet die Autonomie von Personen, die einen problematischen Gebrauch von psychoaktiven Stoffen machen. Wir analysieren den Begriff der Autonomie dieser Subjekte basierend auf medizinischen, psychologischen und moralischen Paradigmen, die den Drogenkonsum entweder als Zwang oder Wahl verstehen. Nachfolgend diskutieren wir dann die psychopathologischen 
Aspekte des Drogenkonsums, vornehmlich die Erfahrung der Temporalität und ihren Einfluss auf die Debatte über die Autonomie dieser Subjekte während ihres Rehabilitationsprozesses.

Schlüsselwörter: Psychoaktive Stoffe, Autonomie, Temporalität, Rehabilitation

Citação/Citation: Leal, E. M.. Muñoz, N. M., \& Serpa Jr., O. D. (2019, março). Além da compulsão e da escolha: autonomia, temporalidade e recuperação pessoal. Revista Latinoamericana de Psicopatologia Fundamental, 22(1), 130-149. http://dx.doi.org/10.1590/ 1415-4714.2018v22n1p130.8.

Editores do artigo/Editors: Profa. Dra. Clarissa de Rosalmeida Dantas

Submetido/Submitted: 28.9.2018/ 9.28.2018 Revisado/Revised: 8.12.2018/12.8.2018

Aceito/Accepted: 14.12.2018/12.14.2018

Copyright: (C) 2009 Associação Universitária de Pesquisa em Psicopatologia Fundamental/ University Association for Research in Fundamental Psychopathology. Este é um artigo de livre acesso, que permite uso irrestrito, distribuição e reprodução em qualquer meio, desde que o autor e a fonte sejam citados / This is an open-access article, which permits unrestricted use, distribution, and reproduction in any medium, provided the original authors and sources are credited.

Financiamento/Funding: Este trabalho não recebeu financiamento / This work received no funding.

Conflito de interesses/Conflict of interest: A autora declara que não há conflito de interesses

\section{Erotildes Maria Leal}

Professora adjunta do Departamento de Medicina de Família e Comunidade da Faculdade de Medicina da Universidade Federal do Rio de Janeiro - UFRJ (Rio de Janeiro, RJ, Br).

Rua Capitão Salomão 68/703 - Botafogo

22271-040 Rio de Janeiro, RJ, Br

https://orcid.org/0002-8468-4571

e-mail: eroleal@gmail.com 


\section{OBSERVANDO A PSIQUIATRIA}

\section{Nuria Malajovich Muñoz}

Professora associada do Instituto de Psiquiatria da Universidade Federal do Rio de Janeiro - UFRJ (Rio de Janeiro, RJ, Br).

Rua General Glicério 326/603 - Laranjeiras

22245-120 Rio de Janeiro, RJ, Br.

https://orcid.org/0000-0003-3872-818X

nuriamalajovich@gmail.com

\section{Octavio Domont de Serpa JR}

Professor associado do Instituto de Psiquiatria da Universidade Federal do Rio de Janeiro - UFRJ (Rio de Janeiro, RJ, Br)

Rua Marquês de São Vicente 51/402 - Gávea

22451-047 Rio de Janeiro, RJ, Br.

https://orcid.org/0000-0001-6827-4057

domserpa@gmail.com

This is an open-access article, which permits unrestricted use, distribution, and reproduction in any medium for non-commercial purposes provided the original authors and sources are credited.

Rev. Latinoam. Psicopat. Fund., São Paulo, 22(1), 130-149, mar. 2019 